\title{
Concordance between nurse-reported quality of care and quality of care as publicly reported by nurse-sensitive indicators
}

Dewi Stalpers ${ }^{1 *}$, Renate A. M. M. Kieft ${ }^{2}$, Dimitri van der Linden ${ }^{3}$, Marian J. Kaljouw ${ }^{4}$ and Marieke J. Schuurmans ${ }^{5}$

\begin{abstract}
Background: Nurse-sensitive indicators and nurses' satisfaction with the quality of care are two commonly used ways to measure quality of nursing care. However, little is known about the relationship between these kinds of measures. This study aimed to examine concordance between nurse-sensitive screening indicators and nurse-perceived quality of care.

Methods: To calculate a composite performance score for each of six Dutch non-university teaching hospitals, the percentage scores of the publicly reported nurse-sensitive indicators: screening of delirium, screening of malnutrition, and pain assessments, were averaged (2011). Nurse-perceived quality ratings were obtained from staff nurses working in the same hospitals by the Dutch Essentials of Magnetism II survey (2010). Concordance between the quality measures was analyzed using Spearman's rank correlation.

Results: The mean screening performances ranged from $63 \%$ to $93 \%$ across the six hospitals. Nurse-perceived quality of care differed significantly between the hospitals, also after adjusting for nursing experience, educational level, and regularity of shifts. The hospitals with high-levels of nurse-perceived quality were also high-performing hospitals according to nurse-sensitive indicators. The relationship was true for high-performing as well as lower-performing hospitals, with strong correlations between the two quality measures $\left(r_{S}=0.943, p=0.005\right)$.

Conclusions: Our findings showed that there is a significant positive association between objectively measured nursesensitive screening indicators and subjectively measured perception of quality. Moreover, the two indicators of quality of nursing care provide corresponding quality rankings. This implies that improving factors that are associated with nurses' perception of what they believe to be quality of care may also lead to better screening processes. Although convergent validity seems to be established, we emphasize that different kinds of quality measures could be used to complement each other, because various stakeholders may assign different values to the quality of nursing care.
\end{abstract}

Keywords: Hospitals, Nurse perception, Nursing care, Quality assessment, Quality indicators, Quality of care

\footnotetext{
* Correspondence: d.stalpers@antoniusziekenhuis.nl

${ }^{1}$ St. Antonius Academy, St. Antonius Hospital Nieuwegein/Utrecht, PO Box

2500, 3430 EM, Nieuwegein, The Netherlands

Full list of author information is available at the end of the article
} 


\section{Background}

Nursing care quality is important, because it is linked to patient safety, patient satisfaction, and other health care outcomes $[1,2]$. However, assessing a multi-faceted concept such as quality of care has many challenges. Quality indicators are commonly used measures to gain insight into health care organizations' performance regarding the quality of care provided. With regard to nursing quality, nurse-sensitive indicators are used, defined as "those outcomes that are relevant, based on nurses' scope and domain of practice, and for which there is empirical evidence linking nursing inputs and interventions to the outcome for patients" [3, 4]. Health care systems across the world use the public reporting of these indicators for benchmarking purposes. Transparency of quality is of great importance for informed decisionmaking by various stakeholders, such as health care providers, consumers, insurance companies and policy makers [5]. As in other countries, all hospitals in the Netherlands annually have to report on a mandatory set of nurse-sensitive indicators. Since 2007, the Dutch Health Care Inspectorate requires hospitals to publicly report indicators, such as delirium, malnutrition, pain and pressure ulcers [6].

In the literature, there is much debate about the reliability and validity of nurse-sensitive indicators. For example, studies by Doran and colleagues [7], and Maas and colleagues [8] showed that nurses are able to collect reliable data regarding indicators (e.g., pain). On the other hand, the need for methodological checks of indicators as accurate measures of quality is also emphasized by various authors [9-11]. To contribute to the existing literature about nurse-sensitive indicators, the aim of the present study is to explore the convergent validity of these quality indicators by examining the correspondence with a nurse-reported measure of quality, namely nurses' perception of the quality of care. Where nursesensitive indicators provide a quantitative basis to monitor and evaluate nursing care and are referred to as objective quality measures, nurse-reported measures are used to determine nurses' perceptions and are referred to as subjective quality measures [12].

Regarding the objective measures, our focus is on nurse-sensitive screening indicators, referring to how often patients' risk identification has taken place after admission to the hospital. Screening of health risks is one of the core duties of nurses and therefore wellsuited as an indicator of care quality [13]. Furthermore, screening indicators are relatively easy to obtain and hospitals can be compared based on their performance without the complex task of adjusting for differences in patients' risks in the various hospitals [14]. We investigated data from six non-university teaching hospitals in the Netherlands. We examined: (i) the performance of each hospital on the following nurse-sensitive screening indicators: delirium, malnutrition, and pain assessments, (ii) nurses' perception of the quality of care; and whether any statistical differences between the hospitals can be ascribed to differences in nurse characteristics, and (iii) whether there is concordance between the two measures of quality of nursing care.

\section{Methods}

\section{Study design and sample}

This cross-sectional study included data from staff nurses working in one of six non-university teaching hospitals located in different parts of the Netherlands. In the Dutch health care setting, teaching hospitals are general hospitals with a transcending regional role and a teaching status. These hospitals are not equal to academic hospitals, as in many other countries (e.g., USA, Canada), because the university based faculty and a specific research role are not present [15]. The data concerning hospital characteristics, such as hospital size (number of licensed beds) and nursing full-time equivalents (FTE) were supplied by the hospital organizations themselves and the Dutch Hospital Association.

\section{Nurses' perception of quality of care}

In the year 2010, the Dutch Nurses' Association issued the Dutch version of the Essentials of Magnetism II survey (D-EoM II) to all contracted staff nurses of the six hospitals. The D-EoM II survey, a validated instrument, asks nurses questions about their work environment, quality of care in their department, job satisfaction, and demographic characteristics $[16,17]$. In this study, we used the scores from the question regarding nurseperceived quality of care: 'On a scale of 1 to 10 , with 1 representing 'dangerously low quality' and 10 representing 'very high quality', how do you rate the quality of patient care in your own hospital unit?' The overall response rate to the survey was $53.3 \%$ and 2338 nurses $(=46.8 \%)$ answered all the questions, including the nurse-perceived quality of care score.

We included the following demographic characteristics of nurses: (i) experience, (ii) education level, and (iii) working shift. Experience in nursing was expressed in years and was categorized per 5 years, ranging from less than 5 years to over 30 years. Nurses' education level was defined as: (i) Registered Nurses (RNs) with an Associate's degree in nursing, (ii) RNs with a Bachelor's degree in nursing, and (iii) RNs with a Bachelor's degree and additional training; with differences regarding complexity of roles and degree of responsibilities [18]. Working shift referred to the kinds of shifts that nurses work, including: (i) fixed shifts (i.e., exclusively day shifts, evening shifts or night shifts), and (ii) rotating shifts. We did not include the effect of gender, because the sample almost exclusively consisted of 
women. We also decided to exclude age from the analyses, because the years of experience were strongly co-related to age.

\section{Nurse-sensitive indicators}

The national database of the Dutch Health Care Inspectorate was used to obtain nurse-sensitive indicator data. At the end of each year, all Dutch hospitals use their internal data management systems to extract the previously defined and legislated quality indicators. The data are publicly reported on a website (www.ziekenhuize ntransparant.nl). In this study, the 2011 dataset was used, including five nurse-sensitive screening indicators concerning delirium, malnutrition, and pain [19]. The definitions and data collection methods are presented in Table 1.

\section{Ethical statement}

This research was executed in compliance with the Helsinki Declaration. The Dutch Hospital Data (DHD) reviewed the study protocol in accordance with the protocol 'DHD-databases use' and with local regulations in the Netherlands (Data Protection Act), and gave formal approval to conduct the study (reference number 12.11.21.01/PH.sdh.). Nurses' participation in the survey study was voluntary and anonymous. It was mentioned to them that completing and submitting the survey automatically meant that they gave informed consent.

\section{Statistical analysis}

First, descriptive statistics were used to characterize the staff nurses in our sample. To test differences in quality scores among stratified groups of nurses, we used analysis of variance (ANOVA) with Bonferroni post-hoc tests (adjusting for multiple comparisons). The assumptions of normally distributed data were met by normality plots of this large sample. We used univariate general linear models (GLM) to analyze differences in perceived quality between the six hospitals; adjusting for the nurse characteristics (experience, education level, working shifts) by including them into the model simultaneously.

To categorize nurse-perceived quality of care, we determined the percentage of satisfied nurses per hospital; the higher the percentage, the higher hospitals' performance. Nurses who gave a quality score of $\geq 8$ (on a scale from 1 to 10) were labeled 'very satisfied,' 'satisfied' refers to $\geq 6-8$ and 'not satisfied' refers to $<6$. Additionally, we ranked the hospitals ranging from $1^{\text {st }}$ to $6^{\text {th }}$, in which the ranking value of $1^{\text {st }}$ represents the highestperforming hospital (i.e., hospital with the highest percentage of satisfied and very satisfied nurses). We considered nurse-perceived quality of care as a subjective measure regarding nursing quality (i.e., influenced by the nurse's personal judgment).

Regarding nurse-sensitive indicators, we calculated a composite score to address each of the six hospitals' performance level. A valid and simple method to compose a composite score is by averaging percentages [20, 21]. The percentages on the five screening indicators, as

Table 1 Definitions of nurse-sensitive screening indicators

\begin{tabular}{|c|c|c|}
\hline Indicators & Definition by numerator-denominator & Data collection \\
\hline \multirow[t]{2}{*}{ Screening of delirium } & $\begin{array}{l}\text { Number of hospital units in which a risk score was included } \\
\text { in the medical record for more than } 80 \% \text { of all patients } \\
70 \text { years and older }\end{array}$ & \multirow[t]{2}{*}{$\begin{array}{l}\text { Collected yearly from hospital unit-based data } \\
\text { management systems. Submitted to the Inspectorate } \\
\text { yearly by hospital organizations. }\end{array}$} \\
\hline & $\begin{array}{l}\text { Total number of hospital units with admitted patients } \\
70 \text { years and older }\end{array}$ & \\
\hline \multirow[t]{2}{*}{ Observation of delirium } & $\begin{array}{l}\text { Number of patients observed at least once using the } \\
\text { measuring methods of DOSS or CAM for the presence of } \\
\text { delirium, regardless of the outcome }\end{array}$ & \multirow[t]{2}{*}{$\begin{array}{l}\text { Collected daily from hospital unit-based data } \\
\text { management systems. Submitted to the Inspectorate } \\
\text { yearly by hospital organizations. }\end{array}$} \\
\hline & $\begin{array}{l}\text { Total number of patients with an increased risk of delirium } \\
\text { ('screening of delirium') }\end{array}$ & \\
\hline \multirow[t]{2}{*}{ Screening of malnutrition } & $\begin{array}{l}\text { Number of adult patients which on admission are screened } \\
\text { for malnutrition }\end{array}$ & \multirow{2}{*}{$\begin{array}{l}\text { Collected daily from hospital unit-based data } \\
\text { management systems. Submitted to the Inspectorate } \\
\text { yearly by hospital organizations. }\end{array}$} \\
\hline & Total number of clinically admitted adult patients in a year & \\
\hline \multirow{2}{*}{$\begin{array}{l}\text { Standardized pain assessment in } \\
\text { post-operative patients in the } \\
\text { recovery room }\end{array}$} & $\begin{array}{l}\text { Number of clinical post-operative patients with a } \\
\text { standardized pain assessment in the recovery room }\end{array}$ & \multirow{2}{*}{$\begin{array}{l}\text { Collected daily from hospital unit-based data } \\
\text { management systems. Submitted to the Inspectorate } \\
\text { yearly by hospital organizations. }\end{array}$} \\
\hline & $\begin{array}{l}\text { Total number of clinical post-operative patients in the re } \\
\text { covery room }\end{array}$ & \\
\hline \multirow{2}{*}{$\begin{array}{l}\text { Standardized pain assessment in } \\
\text { post-operative patients in } \\
\text { hospital units }\end{array}$} & $\begin{array}{l}\text { Number of clinical post-operative patients with a } \\
\text { standardized pain assessment in hospital units }\end{array}$ & \multirow{2}{*}{$\begin{array}{l}\text { Collected daily from hospital unit-based data } \\
\text { management systems. Submitted to the Inspectorate } \\
\text { yearly by hospital organizations. }\end{array}$} \\
\hline & $\begin{array}{l}\text { Total number of clinical post-operative patients in } \\
\text { hospital units }\end{array}$ & \\
\hline
\end{tabular}

Inspectie voor de Gezondheidszorg. Kwaliteitsindicatoren. Basisset ziekenhuizen 2011 [19] 
described by numerator and denominator in Table 1 , were used for this purpose. The composite scores for each hospital were used to categorize the quality of hospitals; the higher the percentage, the higher hospitals' performance. We ranked the hospitals ranging from $1^{\text {st }}$ to $6^{\text {th }}$, in which the ranking values of $1^{\text {st }}$ resembles the highest-performing hospital (i.e., hospital with the highest mean composite score). We considered nursesensitive indicators as objective measures of nursing quality (i.e. involving an impartial measurement, that is, without bias or prejudice).

To test the association between the objective indicators of care and nurses' perception of care, we took the mean composite hospital score on the indicators and correlated that with the percentage of satisfied nurses per hospital. Due to the fact that these analyses were conducted at the hospital-level, we used Spearman's Rho correlation which is the appropriate method in this context as it is known to compare differences in rank-order. All statistical analyses were conducted using SPSS version 22 .

\section{Results}

The characteristics of nurses and the six hospitals are shown in Table 2. Nursing experience ranged between 1 and 40 years, with an average of 16.8 years across the sample. Predominantly nurses had at least a Bachelor's degree $(64.9 \%)$ and were working rotating shifts $(80.6 \%)$. The majority of hospitals were mid-sized; there were two larger hospitals, with more than 1000 licensed beds and more than 1000 nursing FTE.

The mean perceived quality scores for the hospitals ranged from $6.61(S D=1.24)$ to $7.11(S D=1.09)$. There was a strong positive correlation between years of experience and nurse-perceived quality; more experienced nurses were significantly more satisfied than less experienced nurses. Additionally, nurses with 20 to 25 years of experience were most satisfied, followed by nurses with 25 and 30 or more years of experience. RNs with an
Associate's degree were significantly less satisfied as compared to RNs with a Bachelor's degree. Regarding working shifts, it was shown that nurses working fixed shifts were more satisfied than nurses working rotating shifts. Nurses working dayshifts were most satisfied with the quality of care in their hospital. The differences between the six hospitals were significant $[F(5,2332)=$ 8.397; $p<0.01]$ and post-hoc tests revealed that Hospital $\mathrm{C}$ had a significantly lower mean score, as opposed to the other hospitals. These differences could not be attributed to nurse characteristics (experience, education and working shifts), because after controlling for these characteristics the effects remained significant $[F(5$, 2284) $=3.011 ; p=0.01]$.

Table 3 summarizes nurses' perception of quality of care and the ranking of the six hospitals. The majority of nurses were satisfied with the quality of care in their hospital. Approximately $9 \%(N=219)$ were not satisfied and rated the quality of their hospital unit with a score less than 6 . Table 3 indicates that, based on the percentage of satisfied (quality score $\geq 6-8$ ) and very satisfied nurses (quality score $\geq 8$ ), Hospital $\mathrm{D}$ had the best results and Hospital $\mathrm{C}$ had the least favorable results.

Table 4 shows the results regarding the nurse-sensitive indicators. High screening percentages were shown for the indicators of pain; in particular 'pain assessment in the recovery room, with values ranging from 90 to $100 \%$. Large differences between hospitals were found for the screening indicators of malnutrition and delirium; in particular 'observation of delirium', with values between 15 and $100 \%$. Based on the mean composite scores, Hospital D was identified as the highest-performing hospital with a composite score of $93.2 \%$ and Hospital C had the least favorable composite score of $62.9 \%$.

We assessed Spearman's Rho correlations to test the overlap between nurse-perceived quality of care and nursesensitive indicators. A strong significant correlation was shown between the two quality measures of $r_{\mathrm{S}}=0.943$ ( $p=$ 0.005). Hospitals' ranking according to both measures of

Table 2 Demographic characteristics of the study sample

\begin{tabular}{|c|c|c|c|c|c|c|c|c|c|c|c|c|c|c|c|}
\hline & \multirow{3}{*}{$\begin{array}{l}\text { Licensed } \\
\text { beds } \\
\mathrm{N}\end{array}$} & \multirow{3}{*}{$\begin{array}{l}\text { Nursing } \\
\text { FTE } \\
\text { N }\end{array}$} & \multirow{3}{*}{$\begin{array}{l}\text { Nurses } \\
\mathrm{N}\end{array}$} & \multirow{2}{*}{\multicolumn{2}{|c|}{ Experience }} & \multicolumn{6}{|c|}{ Education level } & \multicolumn{4}{|c|}{ Working shifts $^{a}$} \\
\hline & & & & & & \multicolumn{2}{|c|}{ Associate } & \multicolumn{2}{|c|}{ Bachelor } & \multicolumn{2}{|c|}{ Bachelor+ } & \multicolumn{2}{|c|}{ Fixed } & \multicolumn{2}{|c|}{ Rotating } \\
\hline & & & & Mean & SD & $\mathrm{N}$ & $\%$ & $\mathrm{~N}$ & $\%$ & $\mathrm{~N}$ & $\%$ & $\mathrm{~N}$ & $\%$ & $\mathrm{~N}$ & $\%$ \\
\hline All hospitals & & & 2338 & 16.76 & 11.13 & 821 & 35.1 & 1131 & 48.4 & 386 & 16.5 & 447 & 19.4 & 1862 & 80.6 \\
\hline Hospital A & 1102 & 1198 & 452 & 16.54 & 11.50 & 221 & 48.9 & 177 & 39.2 & 54 & 11.9 & 112 & 24.8 & 337 & 74.6 \\
\hline Hospital B & 663 & 808 & 314 & 18.12 & 10.50 & 119 & 37.9 & 146 & 46.5 & 49 & 15.6 & 70 & 22.3 & 237 & 75.5 \\
\hline Hospital C & 696 & 964 & 326 & 14.63 & 10.90 & 123 & 37.7 & 159 & 48.8 & 44 & 13.5 & 52 & 16.0 & 272 & 83.4 \\
\hline Hospital D & 580 & 795 & 348 & 18.49 & 11.34 & 133 & 38.2 & 146 & 42.0 & 69 & 19.8 & 61 & 17.5 & 282 & 81.0 \\
\hline Hospital E & 1070 & 1143 & 595 & 17.80 & 11.00 & 171 & 28.7 & 336 & 56.5 & 88 & 14.8 & 68 & 11.4 & 519 & 87.2 \\
\hline Hospital F & 555 & 813 & 303 & 13.94 & 10.65 & 54 & 17.8 & 167 & 55.1 & 82 & 27.1 & 84 & 27.7 & 215 & 71.0 \\
\hline
\end{tabular}

Bachelors + are RNs with a Bachelor's degree and additional training

${ }^{a}$ Missing values regarding working shifts: All hospitals $(N=29)$, Hospital A (3), Hospital B (7), Hospital C (2), Hospital D (5), Hospital E (8), Hospital F (4) 
Table 3 Ranking by nurses' perception of quality of care

\begin{tabular}{|c|c|c|c|c|c|c|c|}
\hline & All & Hospital A & Hospital B & Hospital C & Hospital D & Hospital E & Hospital F \\
\hline & $N=2338$ & $N=452$ & $N=314$ & $N=326$ & $N=348$ & $N=595$ & $N=303$ \\
\hline \multicolumn{8}{|l|}{ Nurse-perceived quality of care } \\
\hline$\%$ Not satisfied $<6(N)$ & $9.4(219)$ & $10.2(46)$ & $9.6(30)$ & $16.3(53)$ & $6.6(23)$ & $7.4(44)$ & $7.6(23)$ \\
\hline$\%$ Satisfied $\geq 6-8(N)$ & $58.9(1377)$ & $58.8(266)$ & $57.3(180)$ & $62.3(203)$ & $55.7(194)$ & $62.4(371)$ & $53.8(163)$ \\
\hline$\%$ Very satisfied $\geq 8(N)$ & $31.7(742)$ & $31.0(140)$ & $33.1(104)$ & $21.5(70)$ & $37.6(131)$ & $30.3(180)$ & $38.6(117)$ \\
\hline \multicolumn{8}{|l|}{ Ranking } \\
\hline$\%$ Satisfied + very satisfied & 90.6 & 89.8 & 90.4 & 83.8 & 93.3 & 92.7 & 92.4 \\
\hline
\end{tabular}

quality are shown in Table 5 . There was a high degree of correspondence; nurses were generally most satisfied in hospitals with high scores on nurse-sensitive indicators, and least satisfied in lower-scoring hospitals.

\section{Discussion}

Nurse-sensitive indicators are widely used to evaluate the quality of nursing care. The present study examines their convergent validity by investigating concordance between publicly reported nurse-sensitive screening indicators (delirium, malnutrition, pain) and nurse-reported quality of care. To our knowledge, this is one of the first studies to explore the direct relationship between objectively measured quality of nursing care and subjectively measured quality, from a nurses' point of view. We found that there was a substantial correlation between the two quality measures. As such, our study adds knowledge to the international debate on the value of nursesensitive indicators as measures of quality of nursing care.

In literature, there is a scientific debate about the usefulness of publicly reported quality indicators as comparative performance measures. Critics claim that, because nursesensitive indicators are reported by hospital organizations themselves, there is a risk that they adjust the data in order to achieve goals of external accountability [10, 22]. On the other hand, there is evidence that public reporting is associated with actual quality of care $[23,24]$ and stimulates quality improvement activities at the hospital level [25]. In our study, we demonstrated that there is a strong relationship between publicly reported screening indicators and nurses' satisfaction with the quality of care, thereby implicating that these indicators both can be used to assess nursing care quality. However, we emphasize that the two quality measures are not likely to be completely interchangeable. Needleman and colleagues [2] stated that various kinds of quality measures potentially could have their own value for stakeholders. For example, regarding nurse-sensitive indicators, policy makers and insurance companies could use screening indicators to benchmark hospitals and hospital units. Nurse-sensitive screening indicators are particularly suitable for these kinds of purposes, because they are easy to measure and screening activities are a prime task of nurses. Additionally, health care organizations (e.g., hospitals) may benefit more from satisfaction with care ratings, because they provide input for quality improvement in a specific setting. Thus, the

Table 4 Ranking by nurse-sensitive indicators

\begin{tabular}{|c|c|c|c|c|c|c|}
\hline & Hospital A & Hospital B & Hospital C & Hospital D & Hospital E & Hospital F \\
\hline \multicolumn{7}{|l|}{ Quality indicator ${ }^{\mathrm{a}}$} \\
\hline$\%$ Screening delirium & 26.3 & 61.5 & 23.1 & 81.3 & 86.4 & 78.6 \\
\hline ( $N$ screened/total $N$ ) & $(5 / 19)$ & $(8 / 13)$ & $(3 / 13)$ & $(13 / 16)$ & $(19 / 22)$ & $(11 / 14)$ \\
\hline$\%$ Observation delirium & 79.8 & 51.7 & 32.2 & 91.9 & 100.0 & 15.0 \\
\hline ( $N$ observed/total $N$ ) & $(197 / 247)$ & $(45 / 87)$ & $(430 / 1337)$ & $(91 / 99)$ & $(425 / 425)$ & $(9 / 60)$ \\
\hline$\%$ Screening malnutrition & 45.7 & 82.0 & 81.4 & 94.8 & 78.6 & 82.0 \\
\hline$(N$ screened/total $N$ ) & $(6439 / 14095)$ & $(16683 / 20345)$ & $(15175 / 18637)$ & $(16483 / 17379)$ & $(18468 / 23507)$ & $(854 / 1042)$ \\
\hline$\%$ Pain recovery room & 90.1 & 90.0 & 100.0 & 100.0 & 100.0 & 99.7 \\
\hline$(N$ assessed/total $N)$ & $(6418 / 7121)$ & (8087/8986) & (9473/9473) & $(11775 / 11775)$ & (10595/10595) & $(8432 / 8456)$ \\
\hline$\%$ Pain hospital units & 83.7 & 99.4 & 78.0 & 98.1 & 97.1 & 59.0 \\
\hline$(N$ assessed/total $N)$ & $(13045 / 15583)$ & (8932/8986) & (7388/9473) & $(1411 / 1439)$ & $(10943 / 11272)$ & (4428/7505) \\
\hline \multicolumn{7}{|l|}{ Ranking } \\
\hline Composite score & 65.1 & 76.9 & 62.9 & 93.2 & 92.4 & 66.9 \\
\hline
\end{tabular}

${ }^{a}$ Nurse-sensitive screening indicators (see definitions Table 1) 
Table 5 Ranking of quality of nursing care in six Dutch hospitals

\begin{tabular}{lllll}
\hline & Subjectively measured quality & Objectively measured quality & Ranking nurse-perceived quality & Ranking nurse-sensitive indicators \\
\hline Hospital A & 89.8 & 65.1 & $5^{\text {th }}$ & $5^{\text {th }}$ \\
Hospital B & 90.4 & 76.9 & $4^{\text {th }}$ & $3^{\text {rd }}$ \\
Hospital C & 83.8 & 62.9 & $6^{\text {th }}$ & $6^{\text {th }}$ \\
Hospital D & 93.3 & 93.2 & $1^{\text {st }}$ & $1^{\text {st }}$ \\
Hospital E & 92.7 & 92.4 & $2^{\text {nd }}$ & $2^{\text {nd }}$ \\
Hospital F & 92.4 & 66.9 & $3^{\text {rd }}$ & $4^{\text {th }}$ \\
\hline
\end{tabular}

Rank $1^{\text {st }}$ denotes the best result, and $6^{\text {th }}$ the least favorable result

optimal approach for defining quality of nursing care depends on the underlying question and who poses the question.

Comparing objective versus subjective measures is increasingly relevant in current health care research. Previous studies demonstrated significant associations between hospital performance and patient-perceived quality. For example, Jaipaul et al. [26] reported lower mortality rates in hospitals with higher patient satisfaction with overall quality, and Nelson et al. [27] found that hospitals' financial performance was associated with patients' perception of quality of care. With regard to nurse-perceived quality, some studies elaborated on the relationship with medical performance indicators. McHugh and Witkoski Stimpfel [28] examined the convergent validity of nurse-reported quality by analyzing the correspondence with composite scores for processes related to acute myocardial infarction, pneumonia, and surgical patients. They reported that a $10 \%$ increase in nurses' satisfaction with the quality of care was associated with a 0.6 to 2.0 point increase in composite performance scores. Tvedt et al. [29] found significant correlations between nursereported quality and survival probabilities after stroke or acute myocardial infarction. Despite their relevance, these studies solely focused on medical performances. They did not exclusively focus on quality related to nurse-specific indicators (i.e., nurse-sensitive screening indicators). Future research about the usefulness of nurse-sensitive indicators as quality measures can contribute to a better understanding of quality of nursing care.

Our results that Bachelor's educated nurses and more experienced nurses were mostly satisfied about quality of care is the opposite of what previous studies found (e.g., $[17,30])$. We do not have a reasonable explanation for these differences, and therefore more studies assessing educational level and years of experience in relation to nurses' perception of quality should be performed. The kinds of shifts that nurses are working has not often been included as a nurse characteristic. We found that nurses working fixed shifts, especially day shifts were more satisfied that those working rotating shifts. An interpretation is that nurses working rotating shifts may have a fragmented perspective of the quality of care, because of the rotating shift schedule. According to our results, the differences between the individual hospitals could not be explained by the included nurse characteristics. There is ample evidence that other factors, such as leadership, autonomy and nurse-physician relationships are important in relation to nurse-perceived quality and other quality outcomes (e.g., $[17,31])$. The influence of these kinds of work environment factors however, was not the main focus of the present study.

\section{Limitations}

One of the limitations is that, due to missing values on indicators, we were not able to calculate a composite score for each of the six hospitals in 2010. As a result, the nurse-sensitive indicator data were derived in 2011, whereas the survey data of nurses were conducted in 2010. We tested intra-correlations for all nurse-sensitive screening indicators in the full population of 93 Dutch hospitals and found moderate correlations $(r=0.59$ to $r=0.67)$ between the years 2010 and 2011. Therefore, we argue that the results of both years are comparable and adequately reflect the Dutch context. Further research in a larger sample is necessary to support out findings, because our study sample was limited to six hospitals. Second, critics claim that it may be more interesting to extract unit-level data instead of hospital-level data, because there may be unit characteristics (e.g., patient complexity, workload) that are influential [22, 32]. Many attempts are made worldwide to benchmark on the unit-level, for example by ways of longitudinal studies on specific indicators, such as patient falls $[33,34]$. However, it takes years before these kinds of processes are adequately implemented; this is an ongoing process which deserves attention $[2,8]$. Third, we used one single-item score to determine satisfaction with quality of care. Although these kinds of quality scores are important indicators of nurses' perspectives, they also have their limits. In line with previous studies [35], it would be useful to further explore interrelations with other satisfaction scores (e.g., recommendation of own hospital, job satisfaction). Fourth, a possible limitation is that some might have reservations about composite scores based on percentages. As described before, is was shown previously that these 
kinds of composite scores are useful measures to evaluate process performance [20, 21].

\section{Conclusions}

Nurse-sensitive quality indicators and nurse-reported quality of care can offer opportunities to differentiate hospitals in terms of quality of nursing care. Our results confirm that quality indicators correspond with nurses' perception of quality, by revealing strong correlations between the objective measurements from publicly reported indicators and nurses' perceived quality of care from a survey. This finding implies that both quality measures are valuable as indicators of hospital performance. Because there is no golden standard to determine nursing care quality, various quality measures could be used by stakeholders (policy makers, health care providers etc.) to complement each other. All in light of the overarching goal of provision of excellent quality of care to patients.

\section{Availability of data and materials}

The data supporting the conclusions regarding nurseperceived quality of care are property of the Dutch Nurses' Association and are available on request to the Dutch Nurses' Association. The dataset of the Dutch Health Care Inspectorate supporting the conclusions regarding nurse-sensitive quality indicators is publicly available at http://www.ziekenhuizentransparant.nl/.

\section{Abbreviations}

D-EoM II: Dutch Essentials of Magnetism II; FTE: full-time equivalents; RNs: Registered Nurses.

\section{Competing interests}

The authors declare that they have no competing interests.

\section{Authors' contributions}

DS contributed to the design and realization of the study, coordinated the data collection and analysis, and drafted and revised the manuscript. RK revised the manuscript critically for important intellectual content. DL, MK and MS contributed to the concept and design of the study, helped to draft the manuscript and revised the manuscript critically. All authors read and approved the final manuscript.

\section{Acknowledgements}

The authors would like to thank Brigitte de Brouwer from the Dutch Nurses' Association for her contributions with regard to data collection of the Dutch Essentials of Magnetism II.

\section{Author details \\ ${ }^{1}$ St. Antonius Academy, St. Antonius Hospital Nieuwegein/Utrecht, PO Box 2500, 3430 EM, Nieuwegein, The Netherlands. ${ }^{2}$ Dutch Nurses' Association, PO Box 8212, 3503 RE, Utrecht, The Netherlands. Institute of Psychology, Erasmus University, PO Box 1738, 3000 DR, Rotterdam, The Netherlands. ${ }^{4}$ Dutch Health Care Authority, PO Box 3017, 3502 GA, Utrecht, The Netherlands. ${ }^{5}$ Department of Revalidation, Nursing Science \& Sports, University Medical Centre Utrecht, PO Box 85500, 3508 GA, Utrecht, The Netherlands.}

Received: 27 March 2015 Accepted: 1 April 2016 Published online: 06 April 2016

\section{References}

1. Glickman SW, Boulding W, Manary M, Staelin R, Roe MT, Wolosin RJ, et al. Patient satisfaction and its relationship with clinical quality and inpatient mortality in acute myocardial infarction. Circ Cardiovasc Qual Outcomes. 2010;3(2):188-95. doi:10.1161/CIRCOUTCOMES.109.900597.

2. Needleman J, Kurtzman ET, Kizer KW. Performance measurement of nursing care: state of the science and the current consensus. Med Care Res Rev. 2007;64(2 Suppl):10S-43S.

3. Doran DM. Nursing-sensitive outcomes. The state of the science. 2nd ed. Sudbury: Jones and Bartlett Publishers; 2003.

4. Maas ML, Johnson M, Moorehead S. Classifying nursing-sensitive patient outcomes. Image J Nurs Sch. 1996;28(4):295-301.

5. Dunton N, Gajewski B, Klaus S, Pierson B. The relationship of nursing workforce characteristics to patient outcomes. OJIN. 2007;12(3): Manuscript 3 .

6. Inspectie voor de Gezondheidszorg (IGZ). Basic sets of indicators. Available at: http://www.igz.nl/onderwerpen/handhaving_en_toezicht/ risicoindicatorentoezicht/basissets/index.aspx. Accessed 15 Dec 2015.

7. Doran DM, Harrison MB, Laschinger HS, Hirdes JP, Rukholm E, Sidani S, et al. Nursing-sensitive outcomes data collection in acute care and long-termcare setting. Nurs Res. 2006:55(2 Suppl):S75-81.

8. Maas M, Johnson M, Moorhead S, Reed D, Sweeney S. Evaluation of the reliability and validity of nursing outcomes classification patient outcomes and measures. J Nurs Meas. 2003;11(2):97-117.

9. Alexander GR. Nursing Sensitive Databases: Their existence, challenges, and importance. Med Care Res Rev. 2007;64(2 Suppl):44S-63S.

10. Kurtzman ET, Dawson EM, Johnson JE. The current state of nursing performance measurement, public reporting, and value-based purchasing. Policy Polit Nurs Pract. 2008;9(3):181-91. doi:10.1177/1527154408323042.

11. Nakrem S, Vinsnes AG, Harkless GE, Paulsen B, Seim A. Nursing sensitive quality indicators for nursing home care: international review of literature, policy and practice. Int J Nurs Stud. 2009:46(6):848-57. doi:10.1016/j.jpurstu.2008.11.005.

12. Mainz J. Defining and classifying clinical indicators for quality improvement. Int J Qual Health Care. 2003;15(6):523-30.

13. Agency for Healthcare Research and Quality. Patient safety and quality: An evidence-based handbook for nurses. Publication No. 08-0043. Rockville: AHRQ; 2008.

14. Rubin HR, Pronovost P, Diette GB. The advantages and disadvantages of process-based measures of health care quality. Int J Qual Health Care. 2001; 13(6):469-74.

15. Rijksinstituut voor Volksgezondheid en Milieu (RIVM). Volksgezondheid Toekomst Verkenning, Nationale Atlas Volksgezondheid. Bilthoven: RIVM; 2013.

16. De Brouwer BJM, Kaljouw MJ, Kramer M, Schmalenberg C, Van Achterberg T. Measuring the nursing work environment: translation and psychometric evaluation of the Essentials of Magnetism. Int Nurs Rev. 2014;61(1):99-108. doi: 10.1111/inr.12073.

17. Schmalenberg C, Kramer M. Essentials of a productive nurse work environment. Nurs Res. 2008;57(1):2-13.

18. Grotendorst A, Van Londen J. Gekwalificeerd voor de toekomst. Kwalificatiestructuur en eindtermen voor Verpleging en Verzorging. Zoetermeer/Rijswijk: Ministry of Education, Culture and Science; 1996.

19. Inspectie voor de Gezondheidszorg. Kwaliteitsindicatoren. Basisset ziekenhuizen 2011. Utrecht: Dutch Hospital Data (DHD); 2010.

20. Moore L, Lavoie A, Belcaid A, Bourgeois G, Lapointe J, Sampalis JS, et al. A comparison of methods to obtain a composite performance indicator for evaluating clinical processes in trauma care. J Trauma Acute Care Surg. 2013;74(5):1344-50. doi:10.1097/TA.0b013e31828c32f2.

21. Reeves D, Campbell SM, Adams J, Shekelle PG, Kontopantelis E, Roland MO. Combining multiple indicators of clinical quality: an evaluation of different analytic approaches. Med Care. 2007;45(6):489-96.

22. Burston S, Chaboyer W, Gillespie B. Nurse-sensitive indicators suitable to reflect nursing care quality: a review and discussion of issues. J Clin Nurs. 2014;23(13-14):1785-95. doi:10.1111/jocn.12337.

23. Hibbard JH, Stockard J, Tusler M. Does publicizing hospital performance stimulate quality improvement efforts? Health Aff. 2003;22(2):84-94.

24. Werner R, Stuart E, Polsky D. Public reporting drove quality gains at nursing homes. Health Aff. 2010;29(9):1706-13. doi:10.1377/hlthaff.2009.0556.

25. Fung CH, Lim YW, Mattke S, Damberg C, Shekelle PG. Systematic review: the evidence that publishing patient care performance data improves quality of care. Ann Intern Med. 2008;148(2):111-23. 
26. Jaipaul CK, Rosenthal GE. Do hospitals with lower mortality have higher patient satisfaction? A regional analysis of patients with medical diagnoses. Am J Med Qual. 2003;18(2):59-65.

27. Nelson EC, Rust RT, Zahorik A, Rose RL, Batalden P, Siemanski BA. Do patient perceptions of quality relate to hospital financial performance? I Health Care Mark. 1992;12(4):6-13.

28. McHugh MD, Stimpfel AW. Nurse reported quality of care: a measure of hospital quality. Res Nurs Health. 2012;35(6):566-75. doi:10.1002/nur.21503.

29. Tvedt C, Sjetne IS, Helgeland J, Bukholm G. An observational study: associations between nurse-reported hospital characteristics and estimated 30-day survival probabilities. BMJ Qual Saf. 2014;23(9):757-64. doi:10.1136/ bmjqs-2013-002781.

30. Bai J, Zhang Q, Wang Y, Yu LP, Pei XB, Cheng L, et al. Work environment for Chinese nurses in different types of ICUs: a multisite cross-sectional survey. J Nurs Manag. 2015;23(4):498-509. doi:10.1111/jonm.12163.

31. Djukic M, Kovner CT, Brewer CS, Fatehu FK, Cline DD. Work environment factors other than staffing associated with nurses' ratings of patient care quality. Health Care Manage Rev. 2013;38(2):105-14. doi:10.1097/HMR. 0b013e3182388cc3.

32. Blegen MA. Patient safety in hospital acute care units. Annu Rev Nurs Res. 2006;24:103-25.

33. He J, Dunton N, Staggs V. Unit-level time trends in inpatient fall rates of US hospitals. Med Care. 2012;50(9):801-7. doi:10.1097/MLR.0b013e31825a8b88.

34. Montalvo I. The National Database of Nursing Quality Indicators (NDNQI). OJIN. 2007;12(3):Manuscript 2.

35. Aiken LH, Sermeus W, Van den Heede K, Sloane DM, Busse R, McKee M, et al. Patient safety, satisfaction, and quality of hospital care: cross sectional surveys of nurses and patients in 12 countries in Europe and the United States. BMJ. 2012;344:e1717. doi:10.1136/bmj.e1717.

\section{Submit your next manuscript to BioMed Central and we will help you at every step:}

- We accept pre-submission inquiries

- Our selector tool helps you to find the most relevant journal

- We provide round the clock customer support

- Convenient online submission

- Thorough peer review

- Inclusion in PubMed and all major indexing services

- Maximum visibility for your research

Submit your manuscript at www.biomedcentral.com/submit

C Biomed Central 